\title{
INTRA-OCULAR FRAGMENT OF ALUMINIUM ALLOY TOLERATED FOR 12 YEARS*
}

\author{
BY \\ W. MAY
}

London

DETAILS of this patient are reported since it is so rarely possible to observe the condition of an eye which has retained an aluminium foreign body for a number of years.

\section{Case Report}

A man aged 21 in July, 1944, was riding in a truck which exploded a German mine. His body, especially his face and eyes, was peppered with small fragments of metal. Examination at that time showed a number of lacerations of the face and body, and an opacity in the right lens.

At the base hospital localization by ring $x$-ray showed large numbers of foreign bodies in the soft tissue of the face. A dense foreign body lay in the right orbit above and behind the globe: one other of low radio density was seen within the ring in the antero-posterior view.

In August, 1944, a curette evacuation was performed on the right lens, followed 2 months later by a capsulotomy. Post-operatively vision in the right eye could be improved to $6 / 9$.

In April, 1945, it was noted that the right retina showed large areas of destruction and heavy pigmentation, and the vision was not improved beyond counting fingers.

Examination.-The patient had no further trouble until February, 1956, when he was seen at King's College Hospital out-patient clinic complaining that his right eye had been sore for one day. He was found to have a corneal abrasion, and slit-lamp examination showed a deep anterior chamber, with a herniation of the vitreous through an aperture in the lens capsule; no flare or cells were seen. A mobile brown-coloured foreign body was noted in the inferior angle of the anterior chamber. The iris behind the foreign body was atrophic and had a whitish colour suggesting an "imprint" in the iris (see Figure). Pigmentary changes in the retina could be seen through a very turbid vitreous. An $x$-ray showed numerous opaque foreign bodies in the orbital soft tissues, but the foreign body in the globe did not show.

Treatment.-After the abrasion had healed, on March 29, 1956, the foreign body was removed through a keratome incision, a Meibomian curette being used to lift the fragment out of the anterior chamber. Analysis of the foreign body showed it to be a fragmented mass, partly organic. The residue after incineration gave positive tests for aluminium, with possible traces of iron and magnesium.

Follow-up.-Post-operatively there were no immediate complications, but in April, 1956, a bullous keratitis developed which necessitated a lamellar keratoplasty. Since this operation on June 7,1956 , the patient has had no further trouble; the eye remains white and the graft clear, but the vision cannot be improved beyond 3/60.

* Received for publication January 24, 1957. 


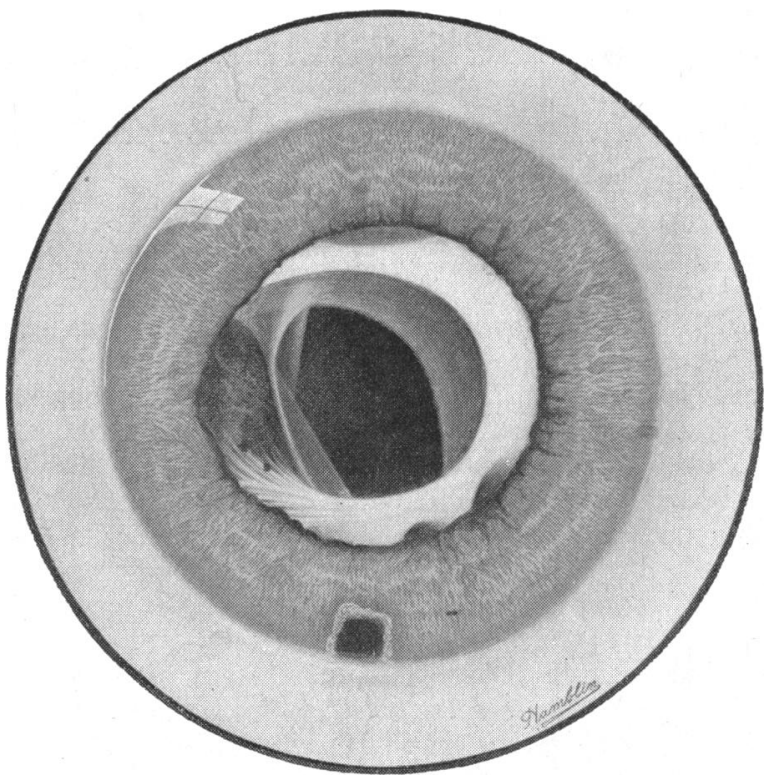

FIGURE.-Appearance of right eye on March 28, 1956. A thick lens capsule can be noted with a large central aperture through which vitreous herniates. The foreign body can be seen in the inferior angle of the anterior chamber as a brown mass surrounded by a grey imprint in the iris stroma.

\section{Discussion}

Savin (1947) showed, by animal experiments on rabbits and observations on two patients, that fragments of aluminium and its alloys, inserted into eyes, became coated with fibrin, and that the metal gradually became fragmented. Local imprints were seen where the metal came into contact with ocular tissues (e.g. the iris) as the result of local necrosis. Lens opacities were commonly seen and a quiet uveitis was present in half the experiments. Pathological fundus pigmentation occurred in many cases. His conclusion was that the eye is by no means inert to aluminium or its alloys.

The case history recorded above showed similar changes in a human eye after an aluminium alloy foreign body had been present for 12 years.

I wish to thank the Chief Medical Officer, Ministry of Pensions and National Insurance, Blackpool, for assistance and for his permission to publish details of this patient's injuries, also Dr. Harold Toms who kindly performed the analysis, and Mr. L. H. Savin under whose care the patient was admitted to hospital.

\section{REFERENCE}

SAVIN, L. H. (1947). British Journal of Ophthalmology, 31, 449. 